\title{
Ethics in physician-assisted dying and euthanasia
}

\author{
Brandi McKinnon MBA, Menfil Orellana-Barrios MD
}

\begin{abstract}
The definitions of physician-assisted dying, passive euthanasia, and active euthanasia are reviewed. The ethical implications of physician-assisted dying are also examined. Proponents argue that physician-assisted dying is a more respectful and dignified way for terminally ill patients to die. However, opponents claim that physician-assisted dying devalues human life, which should be treasured and protected. A majority of the general population and physicians support physician-assisted dying, but there is a need for medical societies to develop training, support, and implementation standards to aid physicians in this process. Ethics committee's may help fill this gap and provide institutional resources and mediation of value conflicts.
\end{abstract}

Keywords: Physician-assisted suicide, physician-assisted dying, euthanasia, medical ethics

\section{INTRODUCTION}

Suffering near the end of life creates anxiety for many terminally ill patients. They experience distressful emotions, such as fear of the future and being a burden to loved ones, and they worry about pain management and the loss of control over the quality of their lives. This has led some terminally ill patients to contemplate and consider physician-assisted suicide, also termed physician-assisted dying, or euthanasia as options toward the end of life. Euthanasia is not legal in the United States; physician-assisted dying is legal in seven states and Washington DC. From the perspectives of patients, there is considerable debate regarding the ethical implications of physician-assisted dying; the patient's self-determination rights, competence, beliefs, and values form the basis for these decisions. In addition, these decisions directly confront the ethical and professional standards of physicians. Therefore, clear and applicable definitions of physician-assisted dying and euthanasia are needed. We have reviewed

Corresponding author: Brandi McKinnon Contact Information: Brandi.Mckinnon@ttuhsc.edu DOI: 10.12746/swrccc.v7i30.561 some definitions and ethical implications that are applicable to health care providers as they relate to physician-assisted dying and euthanasia.

\section{DEFINITIONS}

The definition of physician-assisted dying is conceptually and pragmatically important since multiple and confusing interpretations can arise from the name alone. For the purpose of this review, we will consider physician-assisted dying and physician-assisted suicide as synonymous. The term "physician-assisted dying" is the more acceptable term, opposed to physician-assisted suicide, because "it captures the essence of the process in a more accurately descriptive fashion than the more emotionally charged designation physician-assisted suicide." 1 These nuances in nomenclature may not directly clarify the issues nor do they necessarily change clinical practice, but they do seem to appeal to social, group, and cultural connotations of different terminologies used in these discussions. The American Academy of Hospice and Palliative Medicine defines physician-assisted dying as a physician's providing a lethal dose of a medication that the patient administers to himself or herself with the intention of ending his/her own life. ${ }^{2}$ 
Euthanasia is not as simple to define as physicianassisted dying since two different terms are used. The etymological origin of the term "euthanasia" is from the Greek: eu "well" + thanatos "death". In essence, the word implies good, gentle, or easy death. Euthanasia is defined by Merriam-Webster as: "the act or practice of killing or permitting the death of hopelessly sick or injured individuals (such as persons or domestic animals) in a relatively painless way for reasons of mercy". The Oxford Dictionary's definition is "The painless killing of a patient suffering from an incurable and painful disease or in an irreversible coma."

Two forms of euthanasia should be distinguished: passive and active. Both passive and active euthanasia result in death, but the processes are different. Passive euthanasia refers to hastening the death of an individual by removing active medical support with the intent to produce death and 'actively/intentionally' allowing the terminally ill patient to die naturally. Examples could include turning off ventilators, stopping certain medications, withholding resuscitative efforts (i.e., cardiopulmonary resuscitation), and withholding food and water from the patient. In medical organizations, this decision requires the continued provision of comfort measures. Another form of passive euthanasia is administering pain medication to manage suffering, knowing and intentionally using it to allow the patient to die naturally without support. This is referred to as a double effect. Active euthanasia is defined as causing the death of someone through a direct action at an individual's request. A terminally ill patient, for example, would ask a physician, loved one, or another trusted person to administer a lethal dose of medication, causing the patient's death. This is by far the more ethically challenging form of euthanasia because someone else administers the medication to the patient, and the lethal dose of medication may not necessarily relieve any pain or suffering. Active euthanasia does not truly allow the patient to make this decision for himself, and this has different ethical and legal implications.

Applying ethics to physician-assisted dying, passive euthanasia, and active euthanasia becomes controversial because very different opinions stimulate the debate. The population of the United States includes people from different cultural and religious backgrounds, and there are no uniform religious, moral, and ethical views on this issue. In 1997 the Supreme Court of the United States unanimously ruled that a right to assisted suicide in the United States was not protected by the due process clause in the Constitution since assisted suicide is not a fundamental liberty interest and was not protected under the 14th Amendment. ${ }^{3}$ The Supreme Court concluded that the implementation and regulation of physicianassisted dying should be left to state level legislatures, given the important social and cultural implications. Only eight jurisdictions (Colorado, Hawaii, California, Oregon, Washington, Vermont, New Jersey, and Washington DC) have legalized physician-assisted dying, and no state has legalized active euthanasia. Oregon and Washington legalized physician-assisted dying by popular referendum, Montana by court ruling, and Vermont, Hawaii, New Jersey, and California by legislation. ${ }^{4} \mathrm{~A}$ community or state as a whole must determine whether physician-assisted dying should be legalized, physicians must be willing to do this based on their individual religious beliefs and moral beliefs, and ethical committees should be formed to implement processes that evaluate a patient's request for physician-assisted dying. Processes and standard operating practices must be implemented to determine how the committee will ensure that conflict of interests of the physicians are resolved, beliefs and values of patients are upheld, and a policy on how and by whom physician-assisted dying occurs is in place. Most states allow for physicians and families to make decisions about the type of care a patient is receiving. Passive euthanasia is considered a form of treatment and suffering management (or a change in the goals of care) instead of physician-assisted dying.

\section{DEBATE ON ETHICS OF PHYSICIAN-ASSISTED DYING}

Important questions regarding physician-assisted dying include: Under what circumstances are physicianassisted dying and euthanasia ethical? Should these practices be legal and regulated? When we discuss this issue, we will assume that all patients who would 
be allowed to consider physician-assisted dying or euthanasia are patients whose deaths are imminent and no medical intervention can change that fact. This is a difficult ethical question to answer, and there is no simple black and white answer available. There are many shades of grey, which all depend on a person's upbringing, indoctrination, education, and personal beliefs (moral or religious). Consider this kind of question: Is it ethical for a woman to steal from a grocery store to feed her children? The right or wrong ethical decision would depend on the perspective of the person making that decision. Therefore, shouldn't patients be allowed to make decisions on how they want their lives to end? Terminally ill patients know that life will be over for them in a given span of time. Therefore, whether or not they will die is not in question ... it is whether they have the right to decide in what state and with what dignity they will choose to die.

Federal law has left it up to individual states whether or not physician-assisted dying should be legal. Each state legislature should make decisions on this issue based on case law, precedent, and the beliefs of the majority of people in the state, partly because federal courts do not want to intervene on issues such as this until the consequences have become clearer through the practice and application in individual states. We conclude that the individual person making that decision decides what is ethically right and wrong for himself and that state legislatures should determine if the practice of physician-assisted dying is legal. Therefore, in practice each state decides whether physician-assisted dying is ethical and whether it should be legal based on whether or not the decision reflects the values, morals, and beliefs of the majority of citizens in each state. $^{5}$

Those who believe that terminally ill patients have a right to choose when and by what means they die have very strong feelings about why physicianassisted dying is ethically permissible. Supporters of physician-assisted dying approach this by asking at what point is the quality of life no longer meaningful. According to the Utilitarian theory, it would be ethically appropriate for physician-assisted dying to be a right act because the decision is made in the interest of the patient; the family should not be included except for giving voice to the patient's wishes. ${ }^{6}$ It can be viewed as a greater good because the physician is administering or prescribing medication to be administered to the patient that will eliminate the patient's suffering and/or pain. Proponents of physician-assisted dying, such as Compassion and Choices and the Death with Dignity National Center, both non-profit organizations in the United States, argue that patient autonomy or rational self-determination reduces internal stress and provides control up to the end of life. Under the patient autonomy or rational self-determination principle, proponents maintain that each patient has a right to make autonomous decisions regarding the type of treatment he desires, which includes lethal injection that could result in death. Proponents also maintain that physician-assisted dying relieves pain and suffering. This view means that patients should not have to suffer beyond the limits that they choose. Essentially, proponents advocate that patients have the authority to choose physician-assisted dying as a method of avoiding unnecessary and unwanted pain and suffering.

One argument that might be morally suspect is that legalizing physician-assisted dying would lower costs of health care. However, one report suggested that legalizing physician-assisted dying would save only approximately $1 \%$ of total health care expenditures. ${ }^{7}$ Supporters of physician-assisted dying also claim that a patient's to choosing his own death might allow for organ donation to other people who are not terminal and need transplants. Terminal illnesses cause the deterioration of multiple organs with the eventual loss of function. We can assume, therefore, that proponents find some logic in the need for the living to use these organs while they are still vital when the terminally ill patient is willing to die in a manner that would support another person's chance to live. Therefore, supporters claim that legalizing physician-assisted dying can also save lives. ${ }^{8}$ However, this approach clearly presents very important ethical problems, since it commodifies the value of human life, something that the majority of ethicist in clinical practice would find abhorrent.

The dilemma of whether physician-assisted dying is ethical is unavoidable since opponents hold views 
that physician-assisted dying is inappropriate and wrong. Some opponents view physician-assisted dying as unethical is due to the physicians' Hippocratic Oath of "doing no harm." Opponents view physicianassisted dying as causing harm to patients, which violates the Hippocratic Oath since physicianassisted dying is not a healing proposition. ${ }^{9}$ Opponents can also object to physician-assisted dying because violating the Hippocratic Oath could also lead to a decrease in trust in the patient-physician relationship, since ending a human life is considered to demean life itself. Therefore, eliminating a human life because it will decrease the cost of health care or because suffering and terminal illness are not convenient, as proponents suggest, is disregarding the value that life holds. Another dilemma in legalizing physicianassisted dying is how the medical profession begins to teach medical students and those in residency training how and when it is appropriate to take a human life. If not all physicians have the same beliefs on this issue, we would need to require physicians to be trained in moral reasoning and working with clinical ethicists who could assist with the reasoning through philosophical positions.

Many opponents to physician-assisted dying oppose it based on religious views. For example, the Roman Catholic Church considers the deliberate termination of life as morally wrong and inconsistent with the Fifth Commandment ("Thou shalt not kill"). Judaism considers the preservation of life a great value and does not sanction suicide or assisted suicide. In addition, there is opposition to physicianassisted dying that is not faith-based. First, it can be considered as simply offensive because of the wrongness of killing. Second, it creates a slippery slope that could lead to the risk abuse of others by requesting physician-assisted dying for those who are not terminally ill, such as those who are mentally retarded; some may request physician-assisted dying due to a perception of their lack of quality of life. Third, palliative care specialists claim that pain can be alleviated and that there is no reason to take a human life just to rid someone of pain when that can be achieved without the patient's dying and doing otherwise may risk abandonment. Finally, opponents believe that physician-assisted dying somehow violates physician integrity and patient trust. ${ }^{10}$ These arguments suggest that physicians cannot assume that precipitating death and presumably "limiting suffering" are congruent with a patient's value system. To "aid" patients who are suffering and perhaps not thinking clearly may actually violate their beliefs. This also has the potential of causing unnecessary and premature harm to the loved ones who remain behind.

\section{RATIONAL DECISION MAKING}

Recently, the concept of rational suicide has been presented based on patient autonomy. ${ }^{11}$ Mainstream psychology and psychiatry do not formally consider ending one's life as something rational; however, the need to scrutinize the applicability of physician-assisted dying has required development of certain criteria for the "rationality" of desiring death. In summary, the decision must be voluntary, with evidence of calm deliberation stemming from a clinical scenario considered terminal or irreversible. One potential problem in using "criteria" is the expected ambivalence and changing perceptions/ motivations of those people who will be required to apply these criteria to themselves. ${ }^{12}$ An important study on the implementation of physician-assisted dying was published after the approval of the 1997 Death with Dignity Act legalizing physician-assisted dying in Oregon. The study reported information on 23 patients who received prescriptions for lethal medications with the purpose of ending their lives. Of these, 15 died after taking these medications. The median time from ingestion to death, available dates for 14 patients, was 26 minutes (range 15 minutes - 11.5 hours). No complications were reported with medication use. Case-control analysis of patients with similar terminal illnesses showed no disproportionate use of physician-assisted dying based on the socio-economic, insurance, or education status of the patients. Of course, the conclusions from such a small sample are hard to generalize. ${ }^{13}$ These data have been updated as of $2015 \mathrm{https}: / /$ www.oregon.gov/oha/ph/ProviderPartnerResources/ EvaluationResearch/DeathwithDignityAct/Documents/ year18.pdf. 
When a person has a disease that cannot be cured and is living in severe pain, do you think doctors should or should not be allowed by law to assist the patient to commit suicide if the patient requests it?

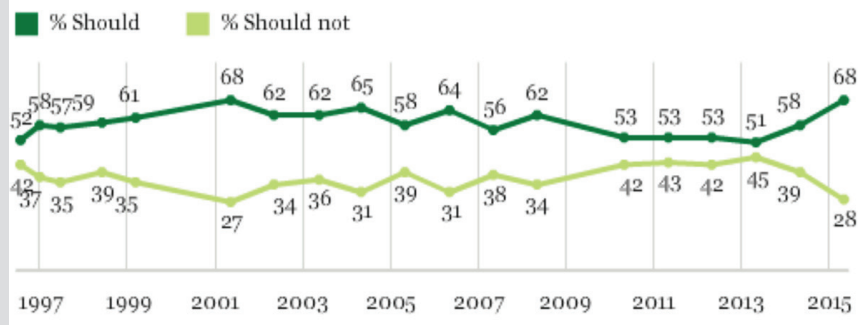

1996-1999 WORDING: When a person has a disease that cannot be cured and is living in severe pain, do you think doctors should be allowed by law to assist the patient to commit suicide if the patient requests it, or not?

More interesting is the fact that the percentage of adults (ages 18 to 34) who support physician-assisted dying rose 19 points from 2014 to a staggering $81 \%$ in 2015 . This definitely shows that younger adults are more likely to support physician-assisted dying than older adults; $80 \%$ of Independents supported physician-assisted dying compared to $61 \%$ of Republicans and $72 \%$ of Democrats. ${ }^{14}$

Legalization of physician-assisted dying must come from individual state legislatures until the federal government decides to rule on this issue. Therefore, public and physician support of physician-assisted dying will be indicators of whether or not states choose to legalize physician-assisted dying. Reviewing some surveys and studies on public support and physician support will be crucial in determining the expected level of support from the general population and the medical community.

\section{Public opinion}

In general, a majority of Americans support physician-assisted dying for specific types of medical patients. However, this support can vary. The results from a 2015 Gallup's Value and Beliefs survey showed a climb in support for euthanasia when compared to the 2014 survey. ${ }^{14}$ The 2015 survey also showed that $68 \%$ of those surveyed support euthanasia with the most notable increase coming from the 18 to 34 -year-old age groups. The survey also indicated that if the word "suicide" was used instead of "death" then support for physician-assisted dying was tempered. The Figure from the Gallup Poll shows that those who support physician-assisted dying has ranged from $52 \%$ to $68 \%$ from 1997 to 2015 and seems to have increased since 2013 (left column).

Physician and provider support for physicianassisted dying reflects that of the general population. In a 2016 survey to physicians on ethics, Lowes noted that $57 \%$ of physicians support physicianassisted dying in terminally ill patients. ${ }^{13}$ This increased $3 \%$ from 2014 and $11 \%$ in 2010 . The change in physician attitudes regarding physician-assisted dying likely represents a greater respect for patient autonomy. Even though there has been a shift in opinion on this issue, it does not mean that physicians do not hold the Hippocratic Oath as sacred. On the contrary, the shift could mean that what physicians and the public view as "harmful" has also shifted. Physicians and the general population have already accepted (legally and culturally) that stopping life-sustaining treatment is acceptable and more often better for the patient. However, physician support evaporates when someone with irremediable suffering is not actively dying. Almost half of physicians surveyed (46\%) opposed physician-assisted dying if the patient is not terminally ill. ${ }^{15}$

\section{Conclusions}

In conclusion, the terms physician-assisted suicide and physician-assisted dying can be considered synonymous, defined as a physician providing lethal doses of medications that patients administer to themselves with the intention of ending their own lives. Euthanasia, to the contrary, can be either passive or active. Passive euthanasia refers to hastening the death of an individual by removing a form of support and allowing the patient to die naturally without support; active euthanasia is causing the death of someone through a direct action at an individual's request. Opponents of physician-assisted dying view this act as causing harm to patients and essentially breaking the Hippocratic Oath. They also oppose it on the belief that taking a life actually devalues and disrespects that which should hold the highest value. Proponents claim that the suffering, anguish, and pain of the patient and family could actually be more harmful. Physicianassisted dying is currently legal in eight jurisdictions in 


\begin{tabular}{|c|c|c|c|}
\hline \multicolumn{4}{|c|}{$\begin{array}{l}\text { When a person has a disease that cannot be cured and is living in severe pain, do you think doctors } \\
\text { should or should not be allowed by law to assist the patient to commit suicide if the patient requests it? }\end{array}$} \\
\hline \% Yes, should be & & & \\
\hline & May 2014 & May 2015 & Change \\
\hline & $\%$ & $\%$ & pct. pts. \\
\hline 18 to 34 years old & 62 & 81 & +19 \\
\hline 35 to 54 years old & 57 & 65 & +8 \\
\hline 55 and older & 56 & 61 & +5 \\
\hline Republicans & 51 & 61 & +10 \\
\hline Independents & 64 & 80 & +16 \\
\hline Democrats & 59 & 72 & +13 \\
\hline
\end{tabular}

\section{GALLUP}

If this public support trend continues, it will not be long before states are forced by constituents to address this ethical debate and create new laws regarding physician-assisted dying.

the United States and has become increasingly more acceptable in the general population as well as among physicians. However, neither the general population nor physicians support physician-assisted dying implementation in non-terminal patients. Therefore, the shift in the viewpoint from both groups shows that there is greater support for patient autonomy and that a majority believe that not allowing patients to suffer in end-oflife is actually more respectful and places more value on the human than the opposite (to allow pain and suffering). In this sense, limiting suffering by precipitating death can be viewed as a better alternative to allowing the natural history of terminal illness. However, even though seven states have made this legal, we must study their methods of implementation and monitor their outcomes to optimize this process. Medical societies will need to develop guidance for providers and provide education to the general public. Most important, consensus guidelines, ${ }^{16}$ certified training, and a databank of regional consultation experts to healthcare systems, providers, and ethics committees may help facilitate the implementation of physician-assisted dying programs. Finally, the public, individuals, families and health care providers need to openly and honestly discuss all aspects of this approach to disease management at the end of life.

Article citation: McKinnon B, Orellana-Barrios M. Ethics in physician-assisted dying and euthanasia. The Southwest Respiratory and Critical Care Chronicles 2019;7(30):36-42

From: The Department of Internal Medicine at Texas Tech University Health Sciences Center in Lubbock, Texas

Submitted: $1 / 24 / 2019$

Accepted: 6/7/2019

Reviewers: Gilbert Berdine MD, Chery Erwin JD, PhD Conflicts of interest: none

This work is licensed under a Creative Commons Attribution-ShareAlike 4.0 International License. 


\section{REFERENCES}

1. Terminology of Assisted Dying-Death With Dignity. 2017; https://www.deathwithdignity.org/terminology/. Accessed Nov 17, 2017.

2. Medicine AAoHaP. Statement on Physician-Assisted Dying AAHPM 2018; http://aahpm.org/positions/pad. Accessed Jan 3, 2018.

3. "Washington v. Glucksberg." Oyez, www.oyez.org/cases/ 1996/96-110. Accessed 23 Apr. 2019.

4. Emanuel E. Euthanasia and physician-assisted suicide: focus on the data. Med J Aust 2017;206(8):339-340.

5. Bix BH. Physician-assisted suicide and federalism. Notre Dame J Law Ethics Public Policy 2003;17(1):53-69.

6. Singer P. Voluntary euthanasia: a utilitarian perspective. Bioethics 2003;17(5-6):526-541.

7. Emanuel EJ, Battin MP. What are the potential cost savings from legalizing physician-assisted suicide? N Engl J Med 1998;339(3):167-172.

8. Ysebaert D, Van Beeumen G, De Greef K, et al. Organ procurement after euthanasia: Belgian experience. Transplant Proc. 2009;41(2):585-586.
9. Boudreau JD. Physician-assisted suicide and euthanasia: can you even imagine teaching medical students how to end their patients' lives? Perm J 2011;15(4):79-84.

10. Sulmasy DP, Travaline JM, Mitchell LA, et al. EW. Nonfaith-based arguments against physician-assisted suicide and euthanasia. Linacre Q. 2016;83(3):246-257.

11. Mayo DJ. The concept of rational suicide. J Med Philos. 1986 May;11(2):143-55.

12. Balasubramaniam $M$. Rational suicide in elderly adults: a clinician's perspective. J Am Geriatr Soc 2018.

13. Chin AE, Hedberg $K$, Higginson GK, et al. Legalized physician-assisted suicide in Oregon-the first year's experience. N Engl J Med 1999;340(7):577-583.

14. Dugan A. In U.S., Support Up for Doctor-Assisted Suicide. Gallup 2015. http://news.gallup.com/poll/183425/supportdoctor-assisted-suicide.aspx.

15. Lowes R. Assisted death: physician support continues to grow. 2016. http://www.medscape.com/viewarticle/ 873844.

16. Frequently Asked Questions. https://www.doh.wa.gov/Youand YourFamily/IllnessandDisease/DeathwithDignityAct/ FrequentlyAskedQuestions. Accessed 4/23/2019 